\title{
THE
}

1986

\section{Submicron silicon powder production in an aerosol reactor}

Jin Jwang Wu

Richard C. Flagan

Otto J. Gregory

University of Rhode Island, ogregory@uri.edu

Follow this and additional works at: https://digitalcommons.uri.edu/che_facpubs

Part of the Chemical Engineering Commons

Terms of Use

All rights reserved under copyright.

\section{Citation/Publisher Attribution}

Wu, J. J., Flagan, R. C., \& Gregory, O. J. (1986). Submicron silicon powder production in an aerosol reactor. Applied Physics Letters, 49(2), 82-84. doi: 10.1063/1.97358

Available at: http://dx.doi.org/10.1063/1.97358

This Article is brought to you for free and open access by the Chemical Engineering at DigitalCommons@URI. It has been accepted for inclusion in Chemical Engineering Faculty Publications by an authorized administrator of DigitalCommons@URI. For more information, please contact digitalcommons@etal.uri.edu. 


\section{Submicron silicon powder production in an aerosol reactor}

Jin Jwang Wu, Richard C. Flagan, and Otto J. Gregory

Citation: Appl. Phys. Lett. 49, 82 (1986); doi: 10.1063/1.97358

View online: https://doi.org/10.1063/1.97358

View Table of Contents: http://aip.scitation.org/toc/apl/49/2

Published by the American Institute of Physics

\section{Articles you may be interested in}

Nanoparticle production in arc generated fireballs of granular silicon powder AIP Advances 2, 012126 (2012); 10.1063/1.3681283

Preparation and analysis of the negative resistance characteristic in an amorphous silicon and silicon-carbide single-barrier device

Applied Physics Letters 65, 2815 (1998); 10.1063/1.112575

\section{PHYSICS TODAY}

MANAGER'S GUIDE

Accelerate R\&D with Multiphysics Simulation

\section{READ NOW}

PRESENTED BY $\checkmark \subset \bigcirc M S O L$ 


\title{
Submicron silicon powder production in an aerosol reactor
}

\author{
Jin Jwang Wu and Richard C. Flagan \\ Division of Engineering and Applied Science, California Institute of Technology, Pasadena, California 91125 \\ Otto J. Gregory \\ Department of Chemical Engineering. University of Rhode Island, Kingston, Rhode Island 0288I \\ (Received 24 February 1986; accepted for publication 19 May 1986)

\begin{abstract}
Powder synthesis by thermally induced vapor phase reactions is described. The powder generated by this technique consists of spherical, nonagglomerated particles of high purity. The particles are uniform in size, in the $0.1-0.2 \mu \mathrm{m}$ size range. Most of the particles are crystalline spheres. A small fraction of the spheres are amorphous. Chain agglomerates account for less than $1 \%$ of the
\end{abstract} \\ spherules.
}

To produce ceramics with high strength at high temperatures, starting powders with carefully controlled properties are required. The ideal powder for such applications would consist of uniformly sized, spherical, nonagglomerated submicron particles with carefully controlled compositions.' These properties make it possible to produce very uniform packing of the starting materials, a critical step in ceramics processing. A variety of methods, including solution synthesis, ${ }^{2,3}$ laser induced reactions, ${ }^{4,5}$ and thermally induced vapor phase reactions, ${ }^{-\infty 10}$ are presently used to generate these starting powders.

The production of uniformly sized, nonagglomerated solid particles of spherical shape by gas phase chemical reactions is possible only under special circumstances. The initial step in particle formation is homogeneous nucleation which generally leads to very high concentrations of very small particles. These particles can grow by Brownian coagulation or by vapor deposition, either chemical or physical. Brownian coagulation of solid particles leads to the formation of low density flocs that may be densified by sintering or vapor deposition. Even if the particles coalesce completely, coagulation leads to a relatively broad particle size distribution, a limiting case of which is the so-called "self-preserving" particle size distribution which maintains its shape as the particles grow. "I

On the other hand, the growth of particles by vapor deposition narrows the particle size distribution as the particles grow. Vapor deposition can dominate over coagulation only when the particle concentration is low since coagulation is a second order process. It is, however, very difficult to prevent the formation of large numbers of particles by homogeneous nucleation of refractory species, even though there may be many particles present in the system.

To generate particles with the desired characteristics, it is therefore necessary to (i) produce particles much smaller than the desired powder size by homogeneous nucleation, with the number concentration being kept low enough to prevent appreciable coagulation, and (ii) grow those particles by deposition of the products of the gas phase chemical reactions that are carried out at such a rate that additional particle formation from the gas is suppressed. As the particles grow by vapor deposition, they depress the vapor pressure of the condensible reaction products and reduce their tendency to nucleate. The influence of growing particles on the nucleation rate has been the subject of numerous theoretical investigations. ${ }^{12-16}$
With this information and knowledge of the reaction kinetics of the system of interest, a reactor can be designed to grow particles with the desired characteristics. Multi-stage reactors have previously been developed in which silicon particles as large as $10 \mu \mathrm{m}$ mass median diameter were grown directly from the products of the thermal pyrolysis of silane on $0.1-1.5 \mu \mathrm{m}$ diameter seed particles by vapor deposition, ${ }^{17,18}$ In the primary particle growth stage of the reactor, the silane pyrolysis was gradually accelerated from a very low value as the particles grew and became more effective at scavenging condensible vapors. This was accomplished by ramping the temperature along the length of the flow reactor.

In this letter, we describe a method for the synthesis of spherical submicron particles of controlled size by thermally induced chemical reactions. This process is applied to the synthesis of silicon powders in the $0.15-0.25 \mu \mathrm{m}$ size range. The properties of these powders are examined.

The synthesis of uniform particles of $0.1 \mu \mathrm{m}$ diameter requires the use of small numbers of much smaller particles as seeds to be grown by vapor deposition. This is accomplished in a single stage reactor in which the reaction rate is initially very low, thereby limiting the size and number concentration generated by nucleation. By ramping the temperature along the length of a flow reactor using the fivezone furnace illustrated in Fig. 1, the rate of reaction is

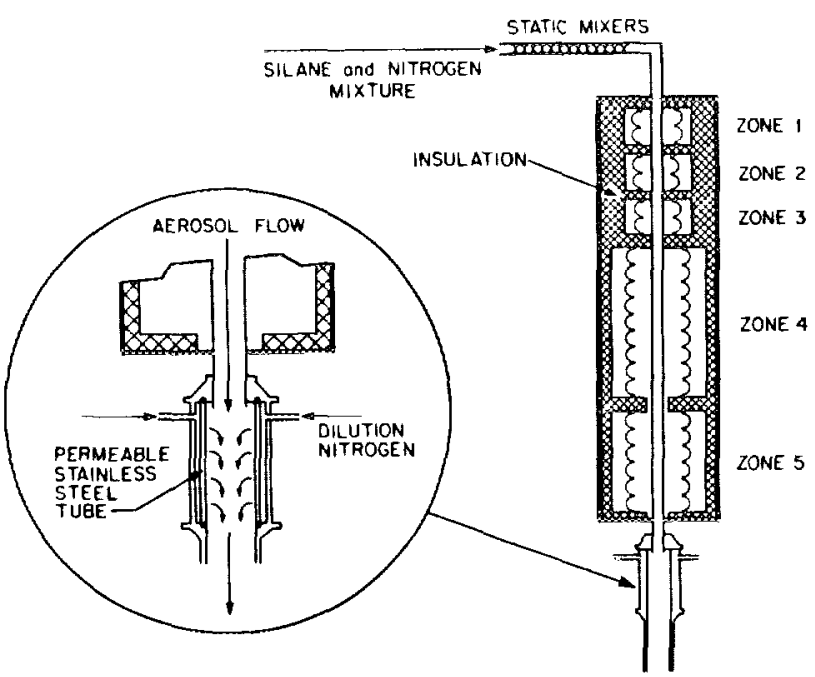

FIG. 1. Schematic of the five-zone aerosol reactor in which silicon particles were generated by silane pyrolysis and the transpired wall system for product dilution and cooling. 


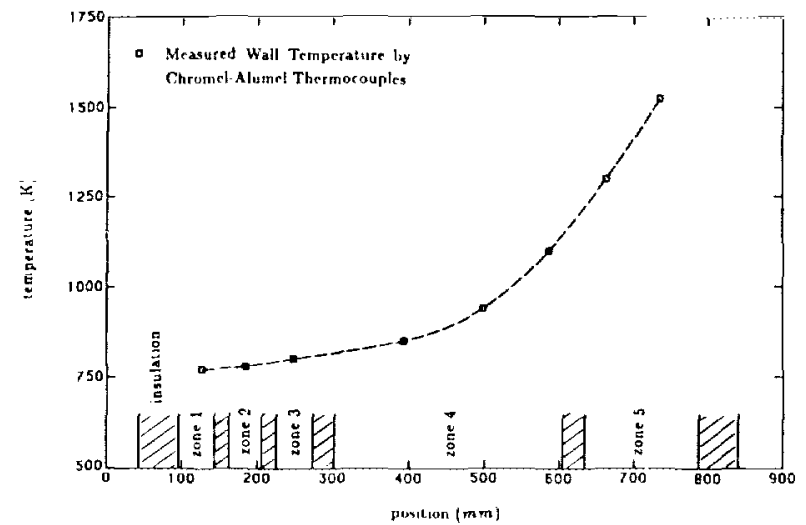

FIG. 2. Measured temperature profiles on the reactor wall. The heating zones and regions of insulation are indicated.

accelerated and the seeds are grown by vapor deposition. The reactor consists of a $12-\mathrm{mm}$-i.d. quartz tube that is 850 $\mathrm{mm}$ long. The first three heating zones are $50 \mathrm{~mm}$ long, and are separated by $10 \mathrm{~mm}$ of low density insulation. The fourth and fifth heating zones are 350 and $150 \mathrm{~mm}$ long, respectively, and again are separated by insulation.

Electronic grade silane (Union Carbide, 99.99\%) and high-purity nitrogen (further purified and dried by passing over hot copper) were thoroughly mixed with a series of static mixers (Luwa, Inc.) and introduced into the upper end of the reactor tube. The temperature of the first furnace zone was maintained at $770 \mathrm{~K}$, to assure a low initial reaction and nucleation rate. This low initial temperature was followed by slow heating, as shown in Fig. 2, to allow time for the nuclei to begin to grow. The temperature at the end of the fourth heating zone was increased to $1100 \mathrm{~K}$, a sufficiently high temperature that complete decomposition was assured. In the remaining length of the furnace the temperature was increased to $1523 \mathrm{~K}$ to densify the silicon particles.

The product aerosol was collected on Teflon membrance filters (Millipore). To prevent thermophoretic deposition of the small particles in the hot reactant flow on the cool walls of the sampling system, the aerosol was first diluted in the porous tube arrangement shown in Fig. 1. By blowing cool (room temperature) nitrogen through the wall of the diluter, the particles are transported away from the vicinity of the wall and high-temperature gradients that would otherwise lead to substantial losses of the product particles.

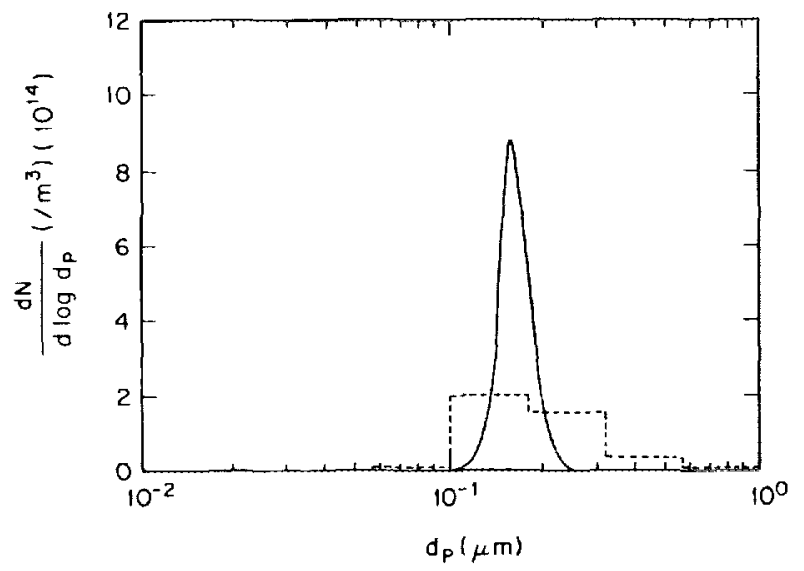

FIG. 3. Number distributions of the product aerosol. The histogram is the raw data obtained with EAA. Also shown is an estimate of the actual particle size distribution obtained by applying a modified Twomey algorithm ${ }^{21}$ to correct for cross sensitivities in the EAA instrument response function.

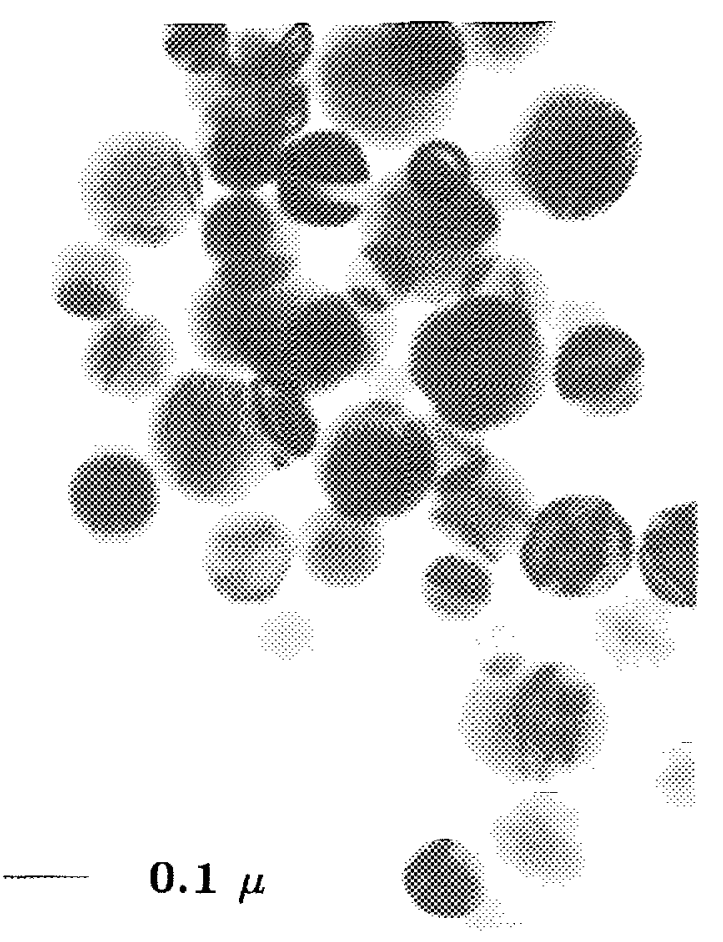

FIG. 4. TEM photographs of the crystalline silicon particles that accounted for about $99 \%$ of the particles produced by rate controlled thermal decomposition of silane.

The filter holders were sealed following collection, and taken to a nitrogen glove box where the silicon was transferred to bottles for storage and shipping.

The size distribution and number concentration of the silicon aerosol at the reactor outlet were measured using a TSI model 3030 electrical aerosol size analyzer, a Royco model 226 laser optical particle counter, and an Environment One condensation nuclei counter. The total number concentration of the product aerosol was $2 \times 10^{14} / \mathrm{m}^{3}$. The size distribution is shown in Fig. 3. The particles were highly uniform in size at about $0.15 \mu \mathrm{m}$ diameter.

The silicon powders were brown in color, indicative of high-purity silicon. ${ }^{19}$ Electron micrographs showed that the particles were dense, spherical, and uniformly sized. The vast majority of the spherules exhibited the morphologies shown in Fig. 4. The structure of these particles consisted of diamond cubic grains with dimensions of $0.05-0.10 \mu \mathrm{m}$

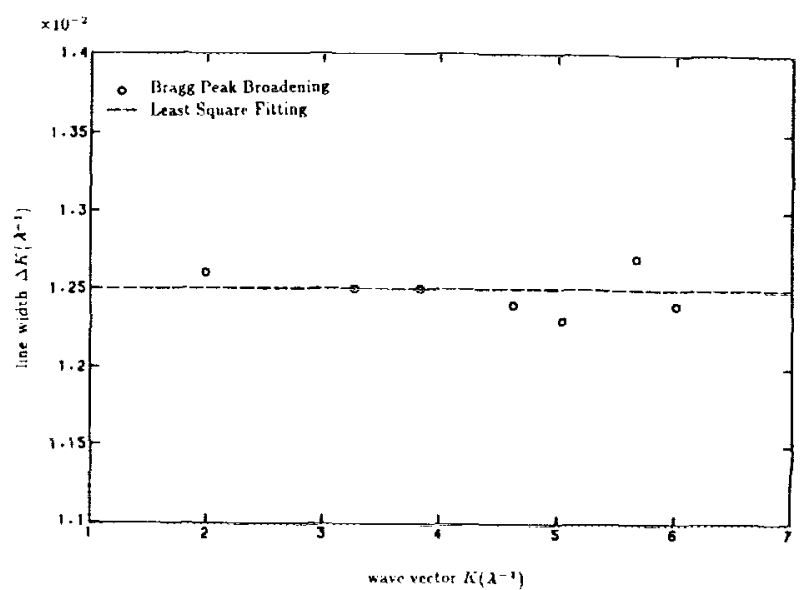

FIG. 5. Bragg peak broadening $\Delta K$ as a function of the magnitude of the wave vector $K$ 


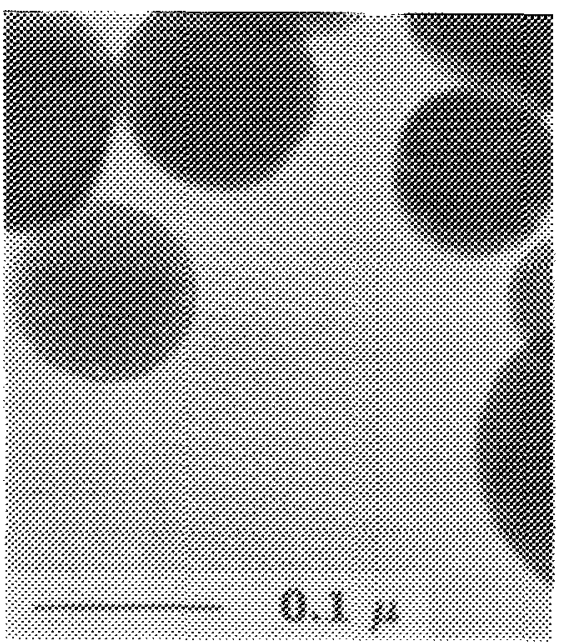

(a)

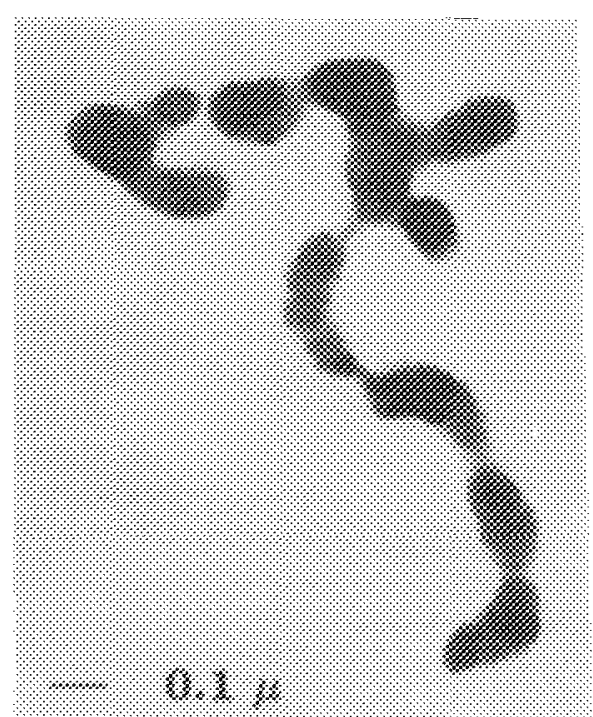

(b) showing extensive twinning and stacking faults. The twin lamellae extend across the entire grain diameter, suggesting that the transformed region sweeps across the entire particle as a planar front upon the amorphous to crystalline phase transformation.

A similar microstructure has been observed during the $\mathrm{ZrO}_{2}$ tetragonal to monoclinic transformation in the system $\mathrm{ZrO}_{2}$-zicron, ${ }^{20}$ which proceeds by a martensitic phase transformation. Frequently associated with these transformations are strain effects due to the large volume changes incurred. These strain effects were not evident in the transformed silicon particles, and there appeared to be little or no distortion of the particles after transformation.

The twinned regions appear to be randomly oriented with respect to neighboring particles, as would be expected for particles that underwent independent processing in the aerosol phase. The average crystallite size was determined from $x$-ray peak broadening. ${ }^{22}$ The Bragg peak broadening $\Delta K$ as a function of the magnitude of the wave vector $K$ was calculated after performing Rachlinger's and Stoke's corrections. ${ }^{22}$ The result, as in Fig. 5, shows that the dominant contribution to the line broadening is from small crystal size. The average crystallite size determined was $50 \mathrm{~nm}$, in close agreement with that estimated from dark field transmission electron microscopy measurements. Based on these measurements, the silicon particles produced by thermal decomposition of silane were 3-4 times as large as the crystallites. This is consistent with measurements made by Cannon et $a l^{4}$ on silicon powders produced by laser induced pyrolysis of silane. The factor controlling the size of these crystallites produced during the amorphous/crystalline transformation is not certain even though there is some evidence that it is similar to a martensitic phase transformation. The particle size to crystallite size ratio appears to be independent of history.

A very small fraction of powders, Fig. 6(a), are featureless, no fine structure. Electron diffraction patterns indicate that these particles are truly amorphous. The amorphous particles could also be distinguished from the crystalline powders by the absence of twins and stacking faults in their microstructures. These essentially featureless powders were unaffected by tilting whereas contrast changes were observed in the twinned regions upon tilting. Chain agglomerates of microcrystalline particles, shown in Fig. 6(b), accounted for less than $1 \%$ of the spherules. Some neck formation was observed in the agglomerates of these spherules.

Infrared absorption spectroscopy was used to explore the possible contamination of the surface with silicon oxides or silicon nitride. No detectable absorption by these species was found. The detection limits for these measurements were estimated to correspond to a layer averaging $7 \AA$ thick on the surface of the particles.

This work was supported in part by the Flat Plate Solar Array Project, Jet Propulsion Laboratory, California Institute of Technology sponsored by the U. S. Department of Energy through an agreement with NASA.

${ }^{1}$ H. K. Bowen, Mater. Sci. Eng. 44, 1 (1980)

'E. A. Barringer and H. K. Bowen, Commun. Am. Ceram. Soc., Decem ber, C-199 (1982).

${ }^{3}$ J. Gobet and E. Matijevic, J. Colloid Interface Sci. 100, 555 (1984).

${ }^{4}$ W. R. Cannon, S. C. Danforth, J. H. Flint, J. S. Haggerty, and R. A. Marra, J. Am. Ceram. Soc. 65, 324 (1982)

'W. R. Cannon, S. C. Danforth, J. S. Haggerty, and R. A. Marra, J. Am. Ceram. Soc. 65, 330 (1982).

${ }^{\circ}$ Y. Suyama and A. Kato, J. Am. Ceram. Soc. 59, 146 (1976).

${ }^{7}$ G. D. Ulrich, Combust. Sci. Technol. 4, 47 (1971).

${ }^{\text {X} G . ~ D . ~ U l r i c h, ~ B . ~ A . ~ M . ~ I n e s, ~ a n d ~ N . ~ S . ~ S u b r a n m a n i a n, ~ C o m b u s t . ~ S c i . ~ T e c h-~}$ nol. 14, 243 (1976)

${ }^{9}$ G. D. Ulrich and N. S. Subranmanian, Combust. Sci. Technol. 17, 119 (1977).

${ }^{10}$ S. Prochazka and C. Greskovich, Am. Ceram. Soc. Bull. 57, 579 (1978).

"F. S. Lai, S. K. Friedlander, J. Pich, and G. M. Hidy, J. Colloid Interface Sci. 39, 395 ( 1972)

12E. M. Zaiser and V. K. LaMer, J. Colloid Sci. 3, 571 ( 1948).

${ }^{13}$ H. Reiss and V. K. LaMer, J. Chem. Phys. 18, 1 (1950)

${ }^{14}$ A. Pesthy, R. C. Flagan, and J. H. Seinfeld, J. Colloid Interface Sci. 82, 465 (1981).

${ }^{15}$ M. K. Alam and R. C. Flagan, J. Colloid Interface Sci. 97, 232 (1984).

${ }^{16}$ J. E. Stern, J. J. Wu, R. C. Flagan, and J. H. Seinfeld, J. Colloid Interface Sci. (in press).

${ }^{17}$ M. K. Alam and R. C. Flagan, Aerosol Sci. Technol. (in press)

${ }^{1 k}$ J. J. Wu and R. C. Flagan (unpublished).

${ }^{19}$ A. J. Moulsen, J. Mater. Sci. 14, 1071 (1979).

${ }^{20}$ R. McPhersen, B. V. Shafer, and A. M. Wang, J. Am. Ceram. Soc. 65, C57 (1985)

${ }^{21}$ G. R. Markowski, Aerosol Sci. Technol. (in press).

${ }^{22}$ B. E. Warren, X-Ray Diffraction (Addison-Wesley, 1969). 